\title{
Perturbaciones sonoras, resonancias visuales: reflexiones sobre el sonido en tres filmes experimentales*
}

\author{
SOUND PERTURBATIONS, VISUAL RESONANCES: REFLECTIONS ABOUT SOUND IN THREE \\ EXPERIMENTAL FILMS
}

PERTURBAÇÕES SONORAS, RESSONÂNCIAS VISUAIS: REFLEXÕES SOBRE O SOM EM TRÊS FILMES EXPERIMENTAIS

\section{Carolina Urrutia Neno** Ana Fernández***}

Cuadernos de Música, Artes Visuales y Artes Escénicas

/ Volumen 14 - Número 1 / Enero - Junio de 2019

/ ISSN 1794-6670 / Bogotá, D.C., Colombia / pp. 65-83

Fecha de recepción: 1 de septiembre de 2018

Fecha de aceptación: 8 de octubre de 2018

Disponible en línea: 28 de diciembre de 2018

doi.org/10.11144/javeriana.mavae14-1.psrv

* Artículo de investigación y reflexión. Se enmarca en el proyecto de investigación “Desbordes de lo real en el cine chileno contemporáneo", financiado por el Consejo Nacional de la Cultura y las Artes, Fondo de Fomento del Audiovisual, Línea de Investigación.

* Licenciada en Estética de la Pontificia Universidad Católica de Chile, magíster en Teoría del Arte y doctora en Filosofía por la Universidad de Chile. Profesora asistente de la Facultad de Comunicaciones, Pontificia Universidad Católica de Chile. ORCID: 0000-0003-4498-0701

*** Licenciada en Arte y en Comunicación Social con título de director audiovisual de la Pontificia Universidad Católica de Chile. ORCID: 0000-0003-0302-2527

\section{Cómo citar:}

Urrutia Neno, Carolina y Ana Fernández. 2018. "Perturbaciones sonoras, resonancias visuales: reflexiones sobre el sonido en tres filmes experimentales." Cuadernos de Música, Artes Visuales y Artes Escénicas 14 (1): 65-83. http://doi.org/10.11144/javeriana.mavae14-1.psrv 


\section{Resumen}

El artículo analiza los imaginarios y espacios sonoros en tres películas chilenas recientes producidas por la productora Diluvio: Lucía (Atallah 2010), Rey (Atallah 2017) y La casa lobo (Cociña y León 2018). A partir de estos filmes, estudiaremos los diversos usos del sonido como un dispositivo estratégico para resignificar tanto las propuestas narrativas como los materiales audiovisuales utilizados. Las películas estudiadas comparten ciertos aspectos de un cine de ficción de tipologías realistas, al modo en que lo comprenden algunos teóricos del realismo, junto con la representación subjetiva y expresiva del cine experimental y expandido. Proponemos una lectura de obra desde el lugar bisagra entre lo cinematográfico y las artes visuales, deteniéndonos en las diferentes prácticas de cada obra, para exponer y contrastar los diferentes usos del sonido que van tensando los modos de trabajar los ruidos, el silencio, el fuera de campo, el sonido de los materiales de expresión y la construcción y destrucción de lo sonoro y lo plástico.

Palabras clave: cine chileno; cine experimental; perturbaciones sonoras; sonido acusmático.

\section{Abstract}

This article analyzes the imaginaries and sound spaces in three recent Chilean films produced by Diluvio productions: Lucía (Atallah 2010), Rey (Atallah 2017), and La casa lobo (Cociña \& León 2018). Based on these films, we will study the diverse uses of sound as a strategic device to re-signify both the narrative proposals as well as the audiovisual material used. The films studied share certain aspects of a fictional cinema of realistic typologies, as understood by some realist theorists, together with the subjective and expressive representation of the experimental and expanded cinema. We propose a reading of the work from the hinge between the cinematographic and the visual arts, pausing at the different practices of each work, in order to expose and contrast the different uses of sound that are tensing the ways of working the noises, the silence, the off camera, the sound of expression materials and the construction and destruction of the sound and the plastic.

Keywords: Chilean films; experimental films; sound perturbations; acousmatic sound.

\section{Resumo}

O artigo analisa os imaginários e espaços sonoros em três filmes chilenos recentes produzidos pela produtora Diluvio: Lucía (Atallah 2010), Rey (Atallah 2017) e La casa lobo (Cociña e León 2018). A partir destes filmes, estudaremos os diversos usos do som como um dispositivo estratégico para ressignificar tanto as propostas narrativas como os materiais audiovisuais utilizados. Os filmes estudados compartilham certos aspectos de um cine de ficção de tipologias realistas, na maneira em que o compreendem alguns teóricos do realismo, junto com a representação subjetiva e expressiva do cine experimental e expandido. Propomos uma leitura de obra a partir da articulação entre o cinematográfico e as artes visuais, detendo-nos nas diferentes práticas de cada obra, para expor e contrastar os diferentes usos do som que vão tensionando os modos de trabalhar os ruídos, o silêncio, o fora de campo, o som dos materiais de expressão e a construção e destruição do sonoro e do plástico.

Palavras-chave: cinema chileno; cinema experimental; perturbações sonoras; som acusmático. 


\section{INTRODUCCIÓN}

Este trabajo propone estudiar la construcción sonora en tres películas chilenas contemporáneas, que mantienen una potente práctica experimental y un anclaje profundo en la animación y en las obras artísticas situadas fuera del circuito de exhibición cinematográfico. Se trata de filmes que están en un espacio intermedio entre las artes visuales y el cine, transitando de forma permanente entre distintos espacios: la instalación audiovisual, la acción real, la animación y la intervención de los materiales de registro. Nos interesa a continuación estudiar los largometrajes Lucía (Atallah 2007), Rey (Atallah 2017) y La casa lobo (Cociña y León 2018).

Las películas escogidas construyen sus poéticas particulares mediante diferentes técnicas, intercalando elementos propios de un cine experimental y vanguardista en sus usos materiales. Se caracterizan por trabajar y repensar el trabajo de archivo, stop motion, la técnica de la rotoscopía análoga, con otras propuestas estéticas y estilísticas que se desvían de un modelo de representación institucional, tal como denomina Noel Burch a un cine que posee una estructura narrativa clásica. ${ }^{1}$ Asimismo, son filmes muy conscientes de la relevancia del sonido y mantienen, en cada caso, una atención particular respecto de la construcción y de los tratamientos sonoros, que operan, o desde una resonancia permanente, o desde un diseño acústico, que no es registrado de modo directo, sino que más bien es configurado para complejizar el estatuto de lo visual, estableciendo de este modo una tensión entre imagen y sonido, y también la anulación total de la jerarquía entre una y otra capa, movilizándose en conjunto y articulando la narración de un modo fundamental para la comprensión de la historia.

Jullier define el sonido como una "perturbación,"2 y en los casos que buscamos analizar, podríamos pensar en una cierta literalidad de esta definición. El autor señala que nuestro cuerpo no percibe el sonido de la misma manera que los estímulos visuales: "El fuera de campo visual existe, pero no el fuera de campo sonoro: tan solo hay sonidos demasiado débiles para ser escuchados" $(2007,4)$. En las películas que estudiaremos, tanto el fuera de campo sonoro como los sonidos acusmáticos ${ }^{3}$ constituyen las principales fuentes de extrañamiento y articulación narrativa (Chion 1993). El sonido de estas obras nos perturba, apela a un imaginario que se manifiesta tanto desde las memorias personales (recuerdos, sensaciones, infancias) como desde lo colectivo (las memorias históricas, las memoriasmundo), apostando por un diseño auditivo que tiende a desbordar lo visual, proponiendo un desajuste entre lo que se ve y lo que se escucha, la puesta en obra de indicios y de síntomas que "hacen ver,"4 pero también que desestabilizan aquello que vemos.

Si bien los largometrajes poseen una propuesta visual novedosa (profundamente extraña dentro del marco de producción de cine chileno), nos interesa detenernos en este artículo especialmente en el campo sonoro que proponen estos filmes, comprendiendo, tal como sugiere el cineasta Robert Bresson, que "imagen y sonido no deben prestarse ayuda, sino trabajar cada uno a su turno, en una especie de relevo" $(1979,58)$. Observamos que las películas seleccionadas procuran instituir un sonido que construye un imaginario a partir de una apuesta acústica, un espacio sonoro que no necesariamente se acopla a la imagen, sino que la complejiza; en unos casos, se distancia y la complementa desde la sugerencia de un espacio off que se desmarca de aquello que pertenece al cuadro visual; en otros reproducen el sonido de la materia prima de las películas y configuran un trabajo sumamente reflexivo en torno a sus mecanismos de enunciación. 


\section{DILUVIO: ESPACIOS INTERMEDIOS Y CAMPOS EXPANDIDOS}

Nos detendremos a continuación en la producción artística y audiovisual de Diluvio, ${ }^{5}$ una casa productora chilena de proyectos artísticos y cinematográficos a cargo de Niles Atallah, Joaquín Cociña y Cristóbal León (directores de las películas seleccionadas), colectivo que funciona como tal desde 2007. Sus cortometrajes, animaciones, videoclips y videoinstalaciones han sido exhibidos en contexto de festivales de cine, de galerías de arte y de museos en varios países, al mismo tiempo que han tenido un circuito de exhibición en salas de cinearte. Un elemento relevante en la obra de este colectivo es la resignificación y valorización de materiales estáticos mediante el uso de técnicas de animación y tratamiento sonoro, en conjunto con una narrativa que se relaciona directamente con estos.

Desde la segunda década del siglo XXI, el cine chileno ha presentado una expansión importante desde el punto de vista de producciones, nuevos directores, alternativas de financiamiento, formatos, circuitos de exhibición y reconocimiento internacional. Estamos frente a un panorama cinematográfico fértil y diverso; no puede establecerse todavía una unidad temática o estilística común, que cruce ficciones con documentales, biografías y relatos intimistas. Las producciones de Diluvio destacan, particularmente, por su aporte a esta diversidad, a partir de sus exploraciones plásticas, trabajo colaborativo con diversos artistas, y desvíos hacia los códigos de las artes visuales y performance, de modo especialmente visible en La casa lobo, su más reciente largometraje. Los modos de trabajo del colectivo distan de lo que podríamos entender como una producción cinematográfica tradicional, no cuentan con un equipo humano estandarizado y subordinado en departamentos sectorizados por oficios (arte, sonido, actores, fotografía, dirección, entre otros), ni con una distribución del trabajo en etapas delimitadas de preproducción, producción, rodaje y posproducción; en este caso, todas las etapas y jerarquías se mezclan y distribuyen en función de la obra. Lo performativo está presente, no solo en lo que se ve en la pantalla, sino en estos modos de producción a baja escala de escenografías construidas en un taller; algunos en formatos más grandes en los que se integra la corporeidad y gestualidad de los animadores en el resultado final, otros en procesos de animación extendidos en el tiempo y en un equipo humano reducido. ${ }^{6}$ Estas acciones se trasladaron a espacios de exhibición artística (museos y galerías de arte) para que los visitantes puedan experimentar in situ los procesos de gestación de sus obras-cortometrajes y, recientemente, largometrajes. El uso de materiales de bajo costo — maderas, carboncillo, objetos cotidianos, plásticos, etc.- en diversos espacios permite una continuidad visual sin depender del territorio en que se instalen, al mismo tiempo que establecen un método de trabajo basado en el ensayo y en el error; hacer, deshacer y rehacer para descubrir resultados en la práctica, en la que los directores cuentan con una sensibilidad particular para conseguir que los materiales comuniquen por sí mismos, a partir de la intervención que realizan sobre ellos y del rol narrativo que se les otorga en el montaje de la película final.

Los cortometrajes previos de Diluvio, realizados en stop motion, Lucía (2007) y Luis (2008), marcan un antecedente de su obra actual; en ambos casos, la voz susurrante de un niño nos guía por una habitación compuesta por objetos domésticos que son intervenidos, adquiriendo movimientos y ritmos que no les son propios. Estos objetos reaccionan a dibujos realizados con carboncillo y otros materiales en las paredes de la habitación, transformándose mutuamente a medida que avanza la historia, según el relato en voz en off. 
Ambos cortometrajes confluyen en una videoinstalación, en la que los materiales y objetos utilizados en ellos fueron desplazados al espacio de exhibición para ser recorrido por sus visitantes. Esta acción que extiende la obra audiovisual más allá de su duración en la pantalla se mantendrá como modo de producción y de presupuesto estético en los filmes que analizaremos.

En los largometrajes realizados por Diluvio, Lucía, Rey y La casa lobo, observamos que las apuestas audiovisuales van desmontando los modos clásicos y hegemónicos de representación y se instalan en el espacio bisagra entre el cine ensayo, el cine experimental y un cine figurativo que tiende a distorsionar - desde una apuesta plástica- lo real. Es un cine en el que el dispositivo material ocupará un lugar principal, que observamos tanto en la propuesta sonora como en el trabajo visual realizado, situado en un espacio particular de reflexión en torno a lo social y a lo político, proponiendo en estos tres casos nuevas narrativas relacionadas con las representaciones de la historia. ${ }^{7}$

Desde el territorio de la ficción, estos filmes exponen novedosos modos de aproximarse a la realidad a partir de eventos pertenecientes al pasado; se trata de una intuición de lo real y de la historia, que deja de lado el naturalismo para pensarse más bien desde una figuración. Una realidad figurada, en estos ejemplos, tendría que ver con los mundos a los cuales apela. En el caso de Lucía, la historia se concentra en la semana en que muere Augusto Pinochet, aludiendo no solo a los estragos causados por el dictador en Chile, sino también a los conflictos y rupturas profundas que permanecen hasta el presente, con la instalación de una economía neoliberal y la sensación de un trauma nunca subsanado. Por su parte, Rey presenta un viaje hacia un pasado remoto: el director y artista visual retrocede en el tiempo para narrar un episodio ambiguo e in-clarificado sobre un francés que viaja a Chile para autodenominarse rey de los mapuches de la Patagonia, con el objetivo de crear un nuevo dominio. Por último, La casa lobo se instala en algún momento de la década de los ochenta, en los tiempos de la dictadura militar, en el sur de Chile, donde se establece la comunidad denominada Colonia Dignidad, ${ }^{8}$ narrando de modo extremadamente ominoso las desventuras de una joven que logra escapar de la colonia. Las películas apelan, en gran medida mediante el sonido, a un real que desborda la narración y excede los límites de la representación, para reclamar una nueva experiencia estética en torno a las propuestas cinematográficas ancladas en nuestra historia.

Como hemos mencionado, desde sus apuestas visuales y sonoras, estos filmes pueden insertarse en la categoría de una obra experimental que va expandiendo sus campos de funcionamiento. Pertenecen a un ámbito en el que las obras "desafían y desarticulan las nociones de la subjetividad, la expectación y el uso del soporte o media, lo que deriva en un tipo de creación amplificada, que comparte miradas y cruces con otras disciplinas " (Di Bella 2018, 95). En este marco, es apropiado pensar en el concepto de "ex" obra para referirse a este tipo de manifestaciones audiovisuales que desbordan los formatos de sus propio medios, precisando que "la creación y producción de una obra experimental existe simultáneamente dentro y fuera del campo de las realizaciones $y$, al exponer tan al desnudo sus modos de producción, permite y posibilita las experimentaciones del juego con las fronteras y poéticas mediante el uso de todos los recursos alternativos" (Lippit 2012, citado por Di Bella 2018, 96). La productora Diluvio busca apropiarse de las diversas zonas artísticas ligadas a la representación, reflexionando sobre el sonido, la imagen y los materiales constitutivos de las obras. 
Estas acciones pueden enmarcarse, igualmente, en el cine expandido de Youngblood, para el autor "un proceso de transformación, el viaje histórico en curso del hombre para manifestar su conciencia fuera de la mente, frente a sus ojos" $(2012,57)$. Dentro de esta obra, podríamos hablar, incluso, de un campo expandido hacia otras áreas, híbridas en el marco de las artes, híbridas en sus procesos de producción y realización, no solo remitiéndose a una expansión tecnológica y a nuevas modalidades de creación, sino también de percepción de la obra que apela, mediante sus propuestas auditivas y visuales, a distintas lógicas sensoriales que van organizando una experiencia estética que se desmarca por completo de los modelos de representación del cine contemporáneo y, particularmente, del cine actual realizado en Chile, incluso de aquel más autoral y autorreflexivo.

Otro autor que trabaja sobre la imagen y los cruces posibles entre fotografía, cine y video, y desde ese vínculo, sus múltiples posibilidades, es Raymond Bellour. En Entre imágenes: foto, cine, video (2009), establece una reflexión entre las bisagras de los distintos lenguajes, centrándose en el "entre" de las imágenes. Nos parece especialmente apropiado para este trabajo aquello que sugiere en su artículo "La doble hélice" (1999), a propósito de las películas de Marker, Resnais, Duras, Godard, entre otros.

No se trata solamente de hablar de la imagen, ni de implicaciones entre la banda de sonido y la banda de la imagen, el lenguaje-texto y la imagen, sino más bien de transformaciones que afectan a la vez a la imagen y al lenguaje, pensamientos directamente uno en relación con otro en tanto que materias.

Observamos en los filmes que acá revisamos una conciencia hacia el medio en el que están trabajando, en esas transformaciones que afectan las distintas partes de las películas y sus distintos materiales de trabajo: desde el congelamiento de los fotogramas para generar extrañeza en el caso de Lucía, la alteración de los negativos del celuloide cuadro a cuadro en Rey, hasta el uso de animación en stop motion exponiendo la factura de los materiales en La casa lobo. En los tres largometrajes, hay una ruptura de la armonía natural de la imagen y el sonido. Por otro lado, estas obras proponen una apuesta indicial en la atmósfera sonora en la que la impresión de lo real será relevante en el momento de tramar la historia, aunque al mismo tiempo hay una puesta en distancia entre lo real y lo imaginario (o lo ficticio) que tendrá un lugar fundamental.

\section{RESONANCIAS, MUTACIONES Y PERTURBACIONES}

En Resonancias filmicas: el sonido en el cine estructural (1960-1981), muy pertinente para este artículo, Alcoz (2017) estudia el cine estructural norteamericano, ${ }^{9}$ señalando lo siguiente:

El cuerpo fílmico propone dialécticas entre la dimensión sonora y la esfera visual, huyendo del carácter naturalista del medio, desfamiliarizando la morfología de sus sonidos. Son manifestaciones fílmicas resueltas como desarrollos formales que, al introducir lógicas estéticas singulares en sus sonidos, amplían el debate del cine como arte, enfatizando en la percepción auditiva. (29) 
En los largometrajes que acá nos ocupan, el sonido adquiere una relevancia fundamental en la construcción de la narración, otorgándole a la historia una dimensión de extrañeza, densidad e in-familiaridad que complementa, sin duda, los elementos intrínsecamente ominosos que son propuestos desde la plasticidad de la imagen. Por ejemplo, en Lucía y La casa lobo, el stop motion opera como un pestañeo, un movimiento lento y aletargado, que convierte la narración en un espacio de ensoñación en el que abunda una confusión que no es exclusivamente visual, sino que encuentra un potente correlato que emerge desde el sonido. Como si de algún modo ambos dispositivos operaran desde lugares distintos, apelando a sensaciones diversas y dando cuenta de la potencia sonora en el momento de marcar la configuración de un fuera de campo o espacio off que excede con creces a la imagen, demandando a las memorias personales del espectador.

El sonido, como veremos, invoca a otros territorios, y funciona no solo activando la imagen, sino también como un cauce en sí mismo, un objeto inmaterial que se propaga fantasmagóricamente. El sonido no solo contextualiza, construye y reconfigura realidades de materiales intrínsecamente silenciosos, contribuyendo a delimitar el marco espacial y temporal de la historia. Los autores de estos filmes manipulan los sonidos, los ralentizan, lo encajan y distancian del flujo visual, trabajando directamente con el tiempo y sus duraciones entumecidas, en una doble dimensión: por un lado, esculpiendo el tiempo en el filme (deteniéndolo, subrayándolo); por otro, sugiriendo otro tiempo, los pasados, los remotos, los recientes. Cada obra a su manera hace énfasis en diferentes aspectos sonoros que marcan la atmósfera, los contextos y los ritmos de cada uno. Lucía y el silencio: el extrañamiento que descontextualiza y destaca cualquier sonido que se levante sobre esa calma. Rey y la construcción sonora de un reino compuesto de naturaleza, voces y el sonido del proyector. La casa lobo y el sonido de los elementos que componen el estatuto material del filme: rasgados del papel y pintura chorreando en el interior de una casa que se fusiona con sus personajes y se transforma, en conjunto con el sonido del mundo exterior, en ese espacio que nunca se muestra.

Estas operaciones podemos trasladarlas a la capa sonora de las películas mencionadas, desde la aproximación a la noción de metaplasmo, ${ }^{10}$ como operación que posibilita una mutación de las formas visuales, desde la entrega de una gran plasticidad a los cuerpos a partir del movimiento. De este modo, el relato va adquiriendo un sentido y existencia en el tiempo mediante un anclaje sonoro, ya que, en este caso, deja de ser una imagen silenciosa y se les otorga propiedades sonoras a objetos que no las tienen. Estas propiedades se desprenden tanto de la materialidad de los objetos como de la narratividad que se construye sobre ellos, al ser animados bajo el contexto de una historia particular.

En los filmes de Diluvio, el sonido no es estable ni constante. Se aproxima a la percepción de cambios, mutaciones y alteraciones orgánicas de un campo sonoro que está vivo, desde los materiales y desde el mundo que existe fuera del campo visual del espectador y de los personajes. Se trata de indicios materializadores que son "los que nos remiten al sentimiento de materialidad de la fuente y al proceso concreto de emisión del sonido" (Chion 1993, 111). Efectivamente, en estos tres filmes, el sonido se aboca a la construcción y existencia física de la obra y opera horizontalmente con las narraciones en off, los sonidos acusmáticos y con el paisaje sonoro. 
Otro tipo de perturbación sonora —volviendo a Jullier — presente en estos filmes es el que incumbe al concepto de ruido:

Por ruido entendemos una complejidad de sonido inarticulado, más o menos fuerte, no deseado. Su consecuencia directa es la dificultad de su descripción verbal [...]. Es en el contexto artístico de los movimientos de vanguardia de principios del siglo XX cuando empiezan a sentarse las bases estéticas que favorecen la consideración del ruido como una forma expresiva autónoma. (Alcoz 2017, 111-112)

Sonidos que en otros contextos pueden ser considerados molestos y que entorpecen la calidad narrativa de un filme (los sonidos invisibilizados del cine institucionalizado y comercial), en este caso se utilizan en función de resaltar la narrativa de la historia y expresividad de los personajes.

Dentro de otras posibles perturbaciones, mutaciones y resonancias, en la percepción sonora, nos interesa la construcción que Deleuze realiza en torno a lo háptico (como fusión de lo óptico y lo táctil), propone el filósofo que "no hay una subordinación estricta en un sentido o en otro [...] cuando la propia vista propone en sí una función de tacto que le es propia" (2002, 158). Integramos acá el sonido como un tercer sentido, teniendo en cuenta lo siguiente: "mientras el sonido porta el significado a algún tipo de información acústica, la háptica muestra el significado referente al comportamiento del instrumento y las acciones del intérprete" (Reyes 2005). Podríamos proponer que en La casa lobo y Lucía la háptica está en el referente material propio del dispositivo utilizado tanto por Atallah como por León y Cociña.

A continuación, nos detendremos en cada una de las películas para analizar cómo los cineastas construyen la propuesta sonora.

\section{“LUCÍA”: SUSPENSIONES Y DESAJUSTES SONOROS}

La ópera prima de Niles Atallah despliega una propuesta visual y sonora muy potente, insertando una primera aproximación por parte del director a las posibilidades de la interacción entre una imagen live action y secuencias de un flujo de fotogramas menor, a modo de cronofotografías, capturando la realidad de ciertas escenas con la técnica stop motion.

La historia gira en torno a Lucía (Gabriela Aguilera), una mujer que vive con su padre (Gregory Cohen), en una casa antigua y destartalada en un sector poniente de Santiago de Chile en el que las viviendas patrimoniales son destruidas para erigir edificios nuevos, de departamentos minúsculos y materiales baratos, que rompen con el diseño urbano de la zona. Los protagonistas serán Lucía, su padre y, como tercer personaje, la casa, ${ }^{11}$ en la que abundan baratijas y objetos que se han ido acumulando a lo largo del tiempo. En este sentido, la temporalidad y sus duraciones será la temática central del filme y de la protagonista, que impide sus posibilidades de movimiento: la sensación permanente es la del estancamiento, en relación con las ruinas del Chile neoliberal, como vestigio de la dictadura, a la cual se alude en varios momentos.

Es interesante el dispositivo experimental, en el que la narración se fractura (se congela en un movimiento extremadamente lento) rompiendo la fluidez temporal de registro naturalista de una ficción cinematográfica. Hay momentos en que la narración se suspende e ingresa en otra categoría, excediendo los bordes de la imagen-tiempo de Deleuze, para 
situarse en otro mecanismo de representación. Cuando esto ocurre (en diversas ocasiones a lo largo del metraje), emerge una luminosidad particular, que convive con el orgánico latido (visual y sonoro) de la casa alrededor de una protagonista inmóvil, que parece estar sometida a ese mismo latido.

El paisaje sonoro se construye aislando los diversos sonidos, que conviven unos con otros: el tictac de un reloj (que palpita como si se tratase de un corazón), el ruido de los autos que transitan por la calle, el murmullo de los niños jugando en algún lugar lejano, las campanillas que probablemente se mecen con el viento, la omnipresencia acústica de los aparatos electrónicos, que zumban, artificialmente, extrañando aún más el ambiente.

Mientras ello ocurre, en el nivel visual se ve a la protagonista sentada en una silla, mirando hacia el vacío. Los planos la exhiben a ella, pero también registran (desde una foto fija, animada cuadro a cuadro) la cocina y el living, en los que convive un número incontable de objetos: muñecas desnudas, calendarios, árboles navideños con sus luces de colores encendidas, manteles plásticos, fotografías, retratos, papeles murales desvencijados, dibujos, entre muchos otros elementos.

El espacio sonoro parece abrazarse a la memoria de los objetos que proponen una trama cartográfica de recuerdos que no le pertenecen solo a la protagonista, sino también a la casa, a las infancias y a los envejecimientos que por ahí han pasado, como un testigo del adentro y el afuera. De Baus (2018) extraemos el término "desajuste sonoro" presente en este título de este apartado. En sus palabras, el sonido en la película Lucía no es "directo y naturalista que represente los estados actuales de los lugares que habitan, sino que, por el contrario, un sonido difuso y sugerente que aflora justamente de entre las intersecciones que se generan en el espacio y la imagen". Se emula un sonido directo y este resuena limpio, volviendo el espacio extraño, a partir de un juego entre sonidos de objetos en el cuadro, pero también de otros acusmáticos, cuya procedencia se mantiene en el fuera de campo, que se tensionan también en una dicotomía permanente entre sonido y silencio.

Hay acá una utilización expresiva del sonido, que apela a otros lugares (temporales, espaciales), que no necesariamente se condicen con aquello que da a ver la imagen. El filme provoca permanentemente el imaginario del fuera de campo, a partir de una poética de la sugerencia, tanto desde los sonidos en campo como desde los sonidos acusmáticos. Hay un momento particularmente poético en que Lucía está recostada en su cama, "animada" a través del stop motion que la moviliza, no solo a ella, sino que también hace que su habitación se estremezca sutilmente. En el nivel sonoro, se oye un río, el piar de las aves, el susurro de los grillos. Luego, cuando la protagonista camina por la habitación, resuena el aleteo de un pájaro, que cruza cercano, y aunque la imagen no lo exhiba, ella pareciera verlo. Son sonidos acusmáticos que mantienen fuera la fuente del sonido, sin embargo, permiten la figuración del espacio imaginario de la protagonista; un lugar otro, alejado, de Lucía, que habita a veces, cuando está sola, como si sus fantasías se revelaran solo en la arena sonora (imaginaria) y no en la real (concreta).

Es interesante cómo la película experimental convive como una operación formal que no se aleja demasiado del realismo cinematográfico. Dicha operación se observa desde el uso de los planos extensos que utiliza el director, los tránsitos de la protagonista por la ciudad, exhibiendo sus conflictos permanentes, sus desigualdades, el lugar en que habitan los ricos y aquellos de una clase olvidada. En ese contexto, la transmisión en off de la TV y de la radio, encendida permanentemente en la casa, será relevante: desde la esfera acústica los 
espectadores nos enteramos, por un lado, de la violencia implícita en el melodrama televisivo que se consume cotidianamente, pero también de lo coyuntural e histórico, a partir de noticiarios que reportean la muerte de Pinochet, y algunos extorturadores que serán conocidos por nuestros protagonistas.

El espacio sonoro de Lucía establece sus códigos narrativos a partir del contraste entre la sincronización y el realismo, con el fuera de campo y con las desincronizaciones sonoras que remiten a la subjetividad de los personajes, desde sus emociones por el tiempo presente y nostalgia por el pasado.

La extrañeza y desfamiliarización operan tanto desde el estrato estético como político de la película, haciendo que el rostro de lo cotidiano y de lo familiar vaya mutando hacia lo sombrío. El sonido acoplado al estilo experimental de la imagen es lo que refuerza la melancolía, la nostalgia, los afectos desplazados hacia lugares del pasado: desde ahí se organiza la atmósfera sentimental, hasta llegar al final del filme, en que el sonido del pasado (de la infancia perdida) registrado en un antiguo casete inunda el plano desde las resonancias que el reproductor emite (figuras 1 y 2 ).
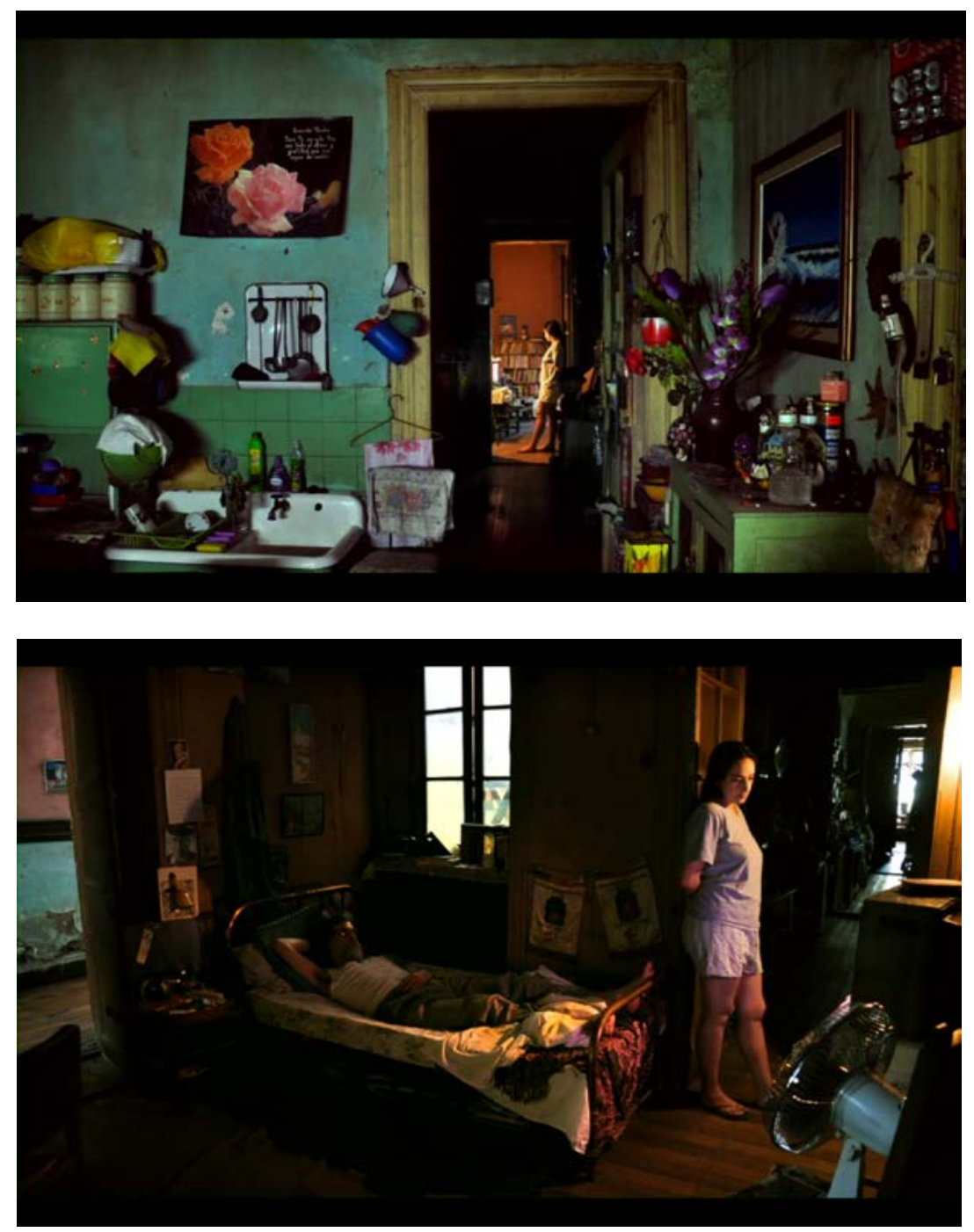

Figuras 1 y 2. Fotogramas. Interiores de la casa de Lucía y su padre. Fuente: Lucía, Atallah, 2007. 


\section{“REY”: FUNDACIÓN DE UN TERRITORIO SONORO}

Rey rescata la indocumentada historia de Orllie-Antoine de Tounens (Rodrigo Lisboa), un abogado de campo francés que llegó al sur de Chile hacia 1860, para instaurar el Reino de la Araucanía y la Patagonia, proclamándose rey con el apoyo de comunidades mapuches. La historia en el filme es contada mediante varias líneas narrativas, a partir del testimonio del protagonista en su juicio y el de Rosales (Claudio Riveros), un campesino chileno que fue su guía en el viaje. Atallah utiliza diversos recursos visuales en diferentes medidas para resaltar las etapas de esta historia, en la que el sonido igualmente muta y se compone de varias capas de sentido. Identificamos tres tipos de relaciones audiovisuales, cada una con diferentes voces y personajes que construyen el viaje del protagonista. Por un lado, están las secuencias que muestran el viaje de Orllie-Antoine en la región de la Araucanía, luego, las escenas del juicio frente a las autoridades chilenas $y$, finalmente, escenas intermedias, que funcionan como transición y como de corriente de la conciencia del protagonista, construidas con material de archivo e intervenciones mediante rotoscopía, ${ }^{12}$ filmados con celuloide. A medida que avanza la historia, estas tres dimensiones visuales y sonoras mutan y mezclan entre sí en un montaje intercalado, trayendo al presente momentos de diferentes tiempos del filme.

En el primer grupo, tenemos al protagonista explorando los bosques y entornos naturales del sur de Chile, con una representación más bien realista. Escuchamos un fondo constante orgánico y natural: insectos, pájaros, viento, agua, plantas, crepitar del fuego; la inmensidad del territorio natural araucano está presente constantemente en esa capa sonora. Ocasionalmente, emerge un sonido acusmático, el golpe de un instrumento de percusión que no vemos, que resalta ciertos momentos. Podemos intuir que se trata de un cultrún, instrumento mapuche, que anticipa su presencia en este territorio. El sonido contribuye a establecer el tipo de espacio en que se desenvolverá el protagonista que va más allá de lo que muestran las imágenes, un bosque enorme, vivo y de límites difusos.

Sobre la presencia sonora del bosque se desenvuelve una multiplicidad de voces, conversaciones que oscilan entre el español, el inglés y el mapudungun. Las barreras idiomáticas de Orllie-Antoine con los mapuches pareciesen no ser un obstáculo para él en cuanto a conformar su reino, sin embargo, desde el otro lado existe una conciencia de ello; no conocer el idioma local implica continuar siendo un extraño y ser ajeno a este territorio. Un momento interesante ocurre cuando el protagonista se encuentra con un mapuche que se comunica con silbidos, imitando a las aves, priorizando lo simbólico de las relaciones con el entorno por sobre la inteligibilidad del lenguaje.

Dar a la voz un tratamiento formal por sobre su utilidad de sentido, de acuerdo con Alcoz, es algo común al cine experimental estructural, "el tratamiento de la voz no se dirige hacia un entendimiento de lo que pueda comunicar aquello pronunciado por el sujeto parlante [...], sino en una interrogación sobre la capacidad comunicativa del lenguaje verbal en su forma registrada" $(2017,157)$. Si bien hemos categorizado estos filmes como experimentales, de todas formas, su afán narrativo resuena con formas más tradicionales, ambas dimensiones del lenguaje conviven, utilizando igualmente el diálogo como recurso para el entendimiento de la historia. En La casa lobo, hay también un tratamiento interesante al respecto, con la voz de un narrador sin cuerpo visible que conversa con los personajes de 
manera amenazante y perturbadora, de modo que es tanto un recurso estilístico como una contribución a la narración. Las voces de la televisión y la radio, presentes constantemente en los interiores de Lucía, pueden leerse igualmente como cuerpos sin forma que entregan información sobre el contexto exterior que queda relegado hacia otro plano.

El segundo grupo de relaciones audiovisuales que mencionamos corresponden a las escenas del juicio, en las que la voz adquiere igualmente un estado predominante. Estas se levantan a partir de una puesta en escena teatral, en un espacio cerrado que puede ser tanto un calabozo, una cueva o un escenario. Predomina la oscuridad y los personajes son resaltados con una iluminación focalizada. Sobre un gran silencio espacial, destacan las voces, los pasos y la respiración de los personajes allí presentes. Toda la atención sonora está en lo que dicen, en cómo se mueven y en cómo interactúan, de modo que esta ausencia de sonido es la que nos desvincula del fondo, pero también la que genera extrañeza e incomodidad frente a la falta de definición del espacio físico que contiene a los personajes. Este extrañamiento también se percibe en Lucía, en que las acciones de ella y su padre resuenan en este interior silencioso y a veces amenazante, el tiempo pareciese transcurrir más lento y de manera ajena al tiempo del resto del mundo; este juicio en La casa lobo pertenece igualmente a un mundo aislado.

A partir de la voz y de los movimientos de los actores, se desprende el modo de funcionar de estas escenas, cuya importancia narrativa es fundamental para el filme (el juicio es el eje central que contiene la linealidad de la historia y adonde volvemos recurrentemente para observar su evolución), que se ve potenciada por el plano sonoro, siempre ligado a lo teatral, voz y acciones que mencionamos, pero ocurriendo un tránsito, desde el sonido propio del juicio como un testigo, hacia la interioridad y angustia del protagonista. A medida que avanzamos en la historia, estos sonidos se tornan cada vez más expresivos: latidos del corazón y respiraciones exageradas nos posicionan en el estado emocional Orllie-Antoine ante la aparente resolución desfavorable de aquel evento. Que este tipo de escenas cuenten con una evolución sonora permite conectar de manera sólida los momentos mencionados.

El último grupo corresponde a las secuencias realizadas con material de archivo y con escenas regrabadas en celuloide e intervenidas. La voz del protagonista comenta sobre aquello que ha presenciado del territorio y vemos imágenes que pareciesen corresponder tanto a este lugar en un tiempo pasado como a los sueños e interpretaciones que Orllie-Antoine hace de este. Cabe mencionar que en los otros grupos escuchamos en ciertos momentos la voz en off del protagonista, contando su viaje e impresiones al respecto en el juicio.

Hacia el final de la película, estos materiales son intervenidos y deformados, integrando también la imagen del protagonista en la batalla final. Para lograr esta apariencia, la intervención del director tuvo varias etapas: se filmó en celuloide varias de las escenas de la película, para luego enterrar las cintas bajo tierra, dejando que se desgasten con el tiempo y la tierra, para luego desenterrarlas y volver a componer todo. En este gesto de rescate visual, reside también el rescate histórico de este personaje que estaba olvidado. En el montaje final, podemos ver el resultado de esta acción mediante el desgaste del celuloide, de modo que también es intervenido con pintura cuadro a cuadro, generando un híbrido de live action con animación.

En la escena final, la batalla, la técnica de rotoscopía análoga se apropia completamente de la imagen y evidencia la intervención manual de cada fotograma, la materialidad de la pintura se sobrepone a la imagen fotográfica, la invade, modifica y transforma, exteriorizando la dimensión caótica de aquel momento, además de deconstruir y dar conciencia al espectador del fotograma, una de las unidades mínimas de la imagen cinematográfica. Técnicamente, 
comparte con el stop motion de Lucía y La casa lobo el tratamiento de la imagen cuadro a cuadro, pero se separa de este en tal forma de ejecución. Estos materiales visuales se activan solo en contraste con el espacio sonoro que fue hecho para esta escena, controlando el ritmo y montaje, resignificando las escenas que le anteceden y preceden. Son múltiples las capas sonoras que interactúan acá para crear esta atmósfera; además de los sonidos propios de la batalla, escuchamos frases en mapudungun y pensamientos del protagonista, reiterando una y otra vez algunas palabras y sonidos hasta perder su sentido. Los sonidos de la naturaleza mutan hasta perderse completamente, alejándonos de la representación visual y sonora realista para entrar en un espacio polifónico psicológico que solo puede serle propio a esta secuencia. Aquí la palabra y la voz se deconstruyen desde la reiteración y superposición de capas, con tratamientos similares a los del cine estructural al que hemos hecho referencia mediante Alcoz.

Al igual como veremos que ocurre con La casa lobo más adelante, es interesante escuchar presente el sonido matérico, en este caso, el ruido de la cinta crepitando al pasar por frente al lente del proyector.

En el grueso del cine experimental la presencia del ruido se invoca como un elemento indisoluble de la experiencia fílmica, algo intrínseco a la puesta en circulación de la materia cinematográfica. Los films estructurales utilizan el ruido de modo expositivo, evidenciando la confusión, promoviendo el equívoco, defendiendo la inexactitud o sugiriendo la incomunicación. (Alcoz 2017, 109)

No queda claro si este sonido del celuloide es insertado o si proviene físicamente de estas secuencias, pero de cualquier forma activa el material fílmico y crea una atmósfera diferente de los otros dos tipos de relaciones audiovisuales, de modo que esta es la más onírica, abstracta y subjetiva, haciendo al espectador partícipe del estado emocional del protagonista. Para contribuir a esta atmósfera, aparecen también sonidos acusmáticos, algunos como una distorsión del espacio ligado a la naturaleza.

Como hemos mencionado, las diferentes dimensiones sonoras de Rey incrementan en intensidad, y se superponen, a medida que avanza el filme, de igual manera en que los recursos visuales evolucionan en el tiempo. Da la sensación de que la capa sonora central son las voces de los personajes, lo que se comunica e interpreta. Esta evolución y sumatoria es gradual, pudiendo notarse un gran contraste del banco sonoro del inicio del filme con el del final, desde silencios y conexión directa imagen-sonido, hacia una superposición de voces, reiteraciones y sonidos expresivos, alejándose el espacio sonoro de lo visual para resignificarse mutuamente. En esta obra, al igual que en Lucía y La casa lobo, el sonido apela a reflexionar sobre el tiempo y la memoria, "excavar" el pasado, imaginar y figurar el pasado, desde un sonido viejo, perteneciente a otra época, a otros tiempos. La representación de la historia, su relectura, tiene un fuerte vínculo con el formato de las tecnologías en desuso, con otros modelos de historización, que contemplan metodologías que no son clásicas para la representación del pasado. Atallah estudia aquello que los libros y la historia dejaron escapar, y toma ese desconocimiento de un evento específico como punto de partida. El final abstracto, alucinatorio, lisérgico, no hace más que subrayar este desconocimiento del pasado y la imposibilidad del cine de aprehender ese fragmento de las historias ${ }^{13}$ (figuras 3 y 4 ). 


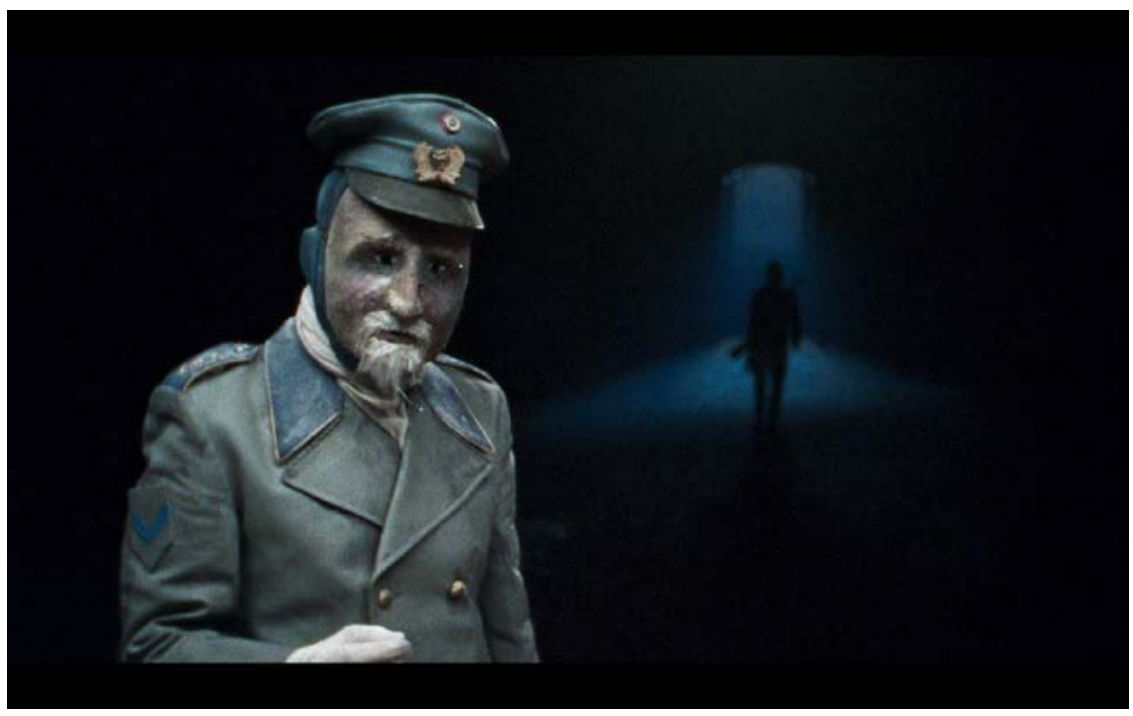

Figura 3. Fotograma de puesta en escena del juicio.

Fuente: http://diluvio.cl/ Acceso el 27 de Abril de 2018.

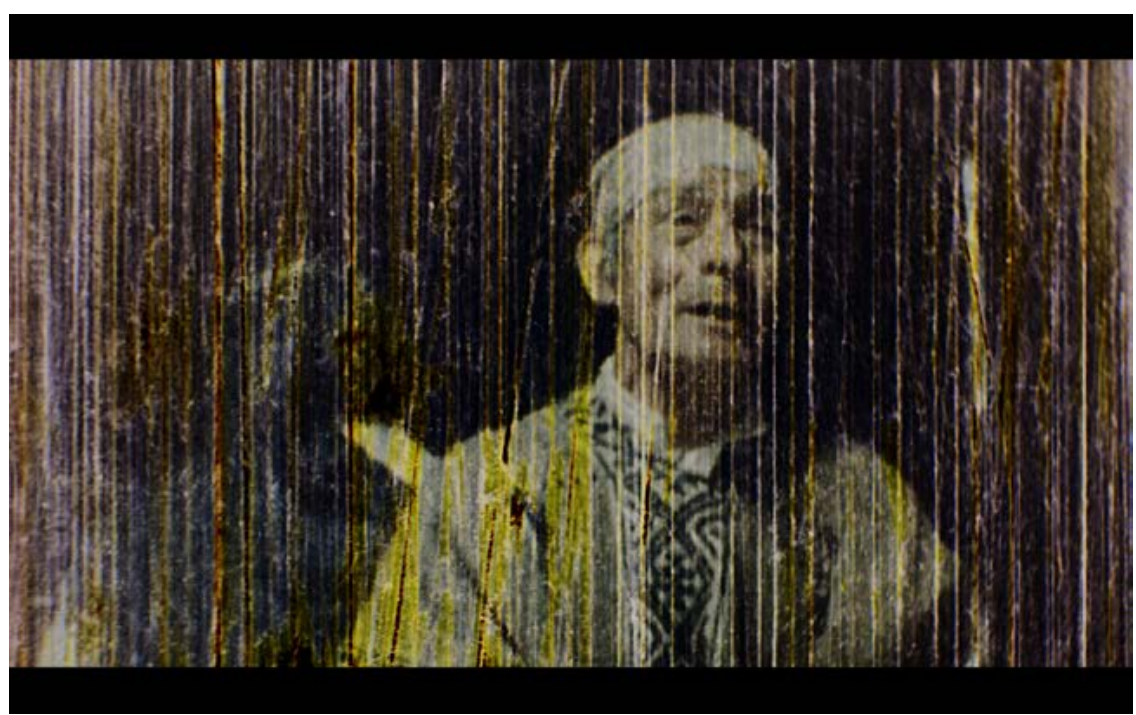

Figura 4. Fotogramas. Deformación y desgaste del celuloide procesado. Fuente: http://diluvio.cl/ Acceso el 27 de Abril de 2018.

\section{“LA CASA LOBO”: MATERIALES SONOROS}

El primer largometraje de la dupla de artistas Joaquín Cociña y Cristóbal León es una animación experimental realizada con la técnica del stop motion, siguiendo una línea de producción de obra profundamente relacionada con la propuesta de la casa productora Diluvio. En la película, los objetos domésticos interactúan con figuras hechas de papel maché, pintura, cinta de embalaje, carboncillo, transformándose cuadro a cuadro en figuras, objetos, personajes. Cada escena de este filme fue grabada en museos o galerías de arte, convirtiendo el espacio de animación en una suerte de acción móvil que se desplaza del cine para ser accesible a los visitantes de las galerías. El resultado es un filme orgánico y cambiante, que muta permanentemente sus formas y figuras a lo largo del metraje. 
Este trabajo anclado a una corriente experimental es también una película de ficción inspirada libremente en un hecho real ocurrido durante la dictadura militar de Chile. Particularmente, hace referencia a los sucesos acontecidos en Colonia Dignidad, un asentamiento emplazado en la zona centro-sur de Chile, fundado por un exmilitar nazi que escapa a Chile por ser acusado en Alemania de abusos sexuales. En Chile, la colonia fue un espacio de abusos y tortura que funcionó durante décadas en complicidad con el régimen militar.

$\mathrm{Ni}$ en términos visuales ni sonoros las referencias a este punto de partida "real" serán literales, a excepción de una introducción preliminar muy breve, realizada desde un trabajo con material de archivo más algunas secuencias registradas especialmente para el filme. Por el contrario, la historia que se narra mucho tiene de fábula infantil (profundamente tenebrosa en su propuesta estética, como suele ocurrir con ese tipo de relatos), que gira en torno al personaje de María, una joven que escapa de la colonia para refugiarse en una casa abandonada e intenta convertirla en su hogar, transformando en ese proceso a dos cerditos en niños que le harán compañía. La alusión a la dictadura será latente y el sonido tendrá un rol central en esta poética de la sugerencia: la atmósfera ominosa adquiere acá una doble dimensión. En primer lugar, dentro del cuadro los elementos aparecen visualmente aterradores (manos que caminan independientemente de los cuerpos, muros en los que aparecen ojos y bocas, costuras que suturan en parte a los rostros). Estos elementos se relacionan con el objetivo de no invisibilizar el dispositivo, sino todo lo contrario: el proceso de construcción queda como una estructura a la vista. En segundo lugar, esta extrañeza se articula desde la puesta en sonido del filme, con muchas capas distintas que van interactuando horizontalmente con los dispositivos visuales.

En relación con aquello que acá nos convoca (las prácticas sonoras de la película), hay que destacar que, a diferencia de otras películas experimentales (poéticas, abstractas, estructurales), en La casa lobo la línea narrativa está profundamente anclada a la voz en off, la palabra hablada que encuentra distintas voces, principalmente en el personaje de María, aunque también en el de su persecutor (el lobo, simbólicamente hablando); y por otro lado, las voces que emergen a rato de los niños/chanchos, que reiteran aquello que dice la protagonista. Se trata en los tres casos de voces no sincrónicas que llegan susurrantes desde un fuera de campo, de modo misterioso, pero también como un acceso al flujo de conciencia de la protagonista. Efectivamente, nunca sabremos a cierta ciencia si las otras voces off (la del lobo y la de los chanchos antropomórficos) son concretas o imaginarias, pertenecientes en este último caso al mundo sensible de la protagonista, como una puerta de entrada a sus emociones, percepciones, pensamientos.

Los susurros de la palabra recitada que se despliegan a lo largo del filme van organizando el sentido narrativo, aunque se trate de un sentido inestable y confuso. Tal como Alcoz propone "es la fiabilidad de la representación de la voz como mecanismo de comunicación lo que se pone en entredicho en unos filmes que buscan la especificad de lo fílmico, desfamiliarizando el uso habitual de la palabra hablada como código útil del relato" $(2017,160)$.

En La casa lobo, la narración en off, por un lado, le da sentido a la imagen propiamente experimental y antirrealista, sin embargo, el resto de los componentes presentes en el tratamiento auditivo del filme van construyendo un paisaje sonoro muy complejo, en el que confluyen diversos dispositivos. En primer lugar, están los sonidos ambientales, que dan cuenta de un espacio mayor a la casa que ocupa María (espacio en el que ocurre por completo la acción), y que se componen de sonidos pastoriles, propios del campo o del bosque, 
con el piar de las aves o el murmullo del río que viene desde lejos. Son indicios, huellas de un paisaje (el sur de Chile), alejado de la ciudad y sus rumores, inmerso en una naturaleza que pareciera estar aislada de la humanidad. En segundo lugar, y de modo permanente durante el metraje, percibimos los sonidos materiales del propio dispositivo de animación de los objetos, decorados y personajes: plásticos que se arrugan, lápices o pinceles que rozan las paredes, cinta adhesiva que se despega de su suporte, entre otros. Aquello que Alcoz denomina "el substrato matérico del sonido" $(2017,91)$ y que supone un grado profundo de autorreferencialidad en los procesos de creación de la producción. ${ }^{14}$ Se trata en su mayoría de ruidos que aluden directamente al trabajo manual de los creadores y no a los ruidos propios del formato audiovisual, como ocurre en el caso de Rey. Esto se vincula, directamente, con el espacio narrativo, ya que tanto los escenarios como los personajes están construidos de los mismos materiales, adquiriendo todo el mismo nivel de organicidad e "ilusión de estar vivos" que la animación entrega a dichos materiales.

Otro sonido relevante en la propuesta estética, de atmósfera hipnótica, es la música extradiegética, que otorga otras perspectivas al relato, cargándola de una emocionalidad adecuada a la propuesta fabulesca, intercalando diversos tipos de melodías que se movilizan entre lo empático en que la música "parece adherirse directamente al sentimiento sugerido por la escena, y en particular al sentimiento que supuestamente están experimentando determinados personajes" (Chion 1995, 232), y lo anempático (como emoción multiplicada), que consiste en este caso en un sonido extremo, que profundiza en la amenaza de un fuera de campo invisible y al cual no podemos acceder desde lo visible (a pesar de que, insistimos, se trata de una imagen permanentemente inquietante). Esta música tendrá un rol fundamental en la conformación de lo siniestro, la amenaza bordeando la imagen, a partir de una propuesta acusmática que se encarga de destruir los sonidos del mundo apacible ya descrito. Lo inunda con sus excesos pavorosos que anuncian al ser monstruoso que nunca deja de estar al acecho de María y los niños, tras la puerta, del otro lado de los muros, en el afuera inaccesible.

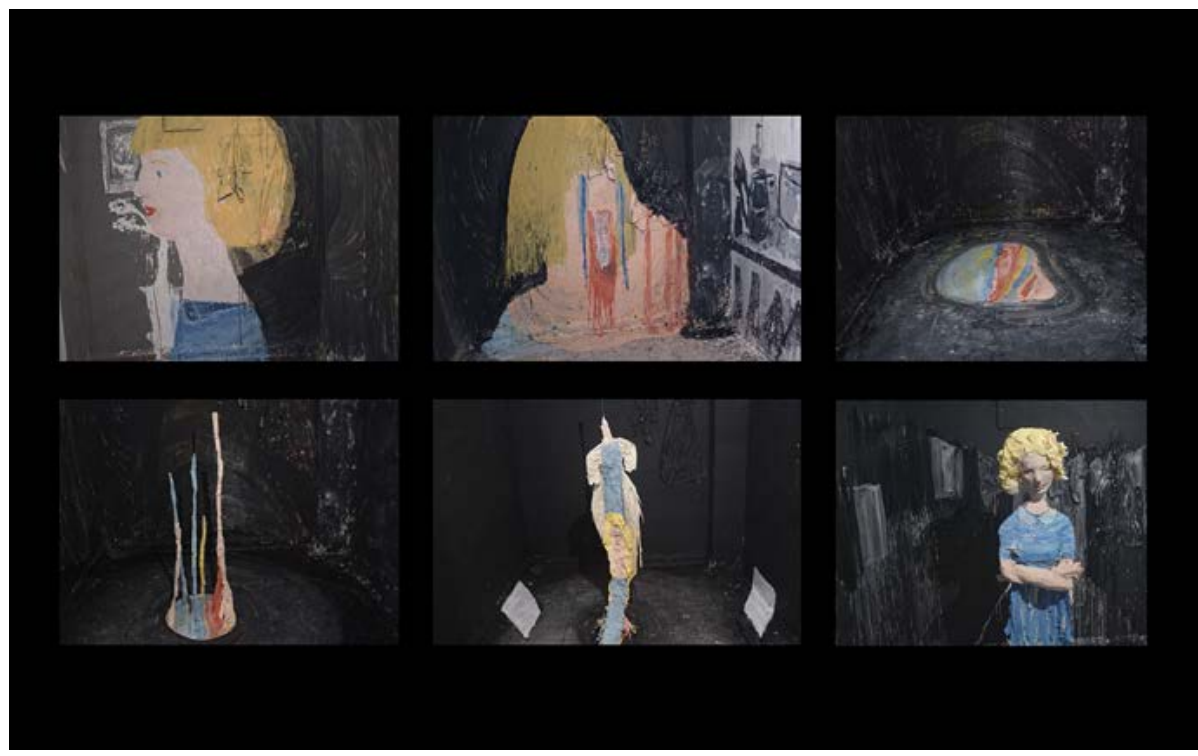

Figura 5. Fotogramas. Secuencia de La Casa Lobo, para dar cuenta de la mutación de los materiales. El personaje tridimensional de María nace a partir de su imagen bidimensional en el muro. Fuente: La Casa Lobo, León y Cociña 2018. 


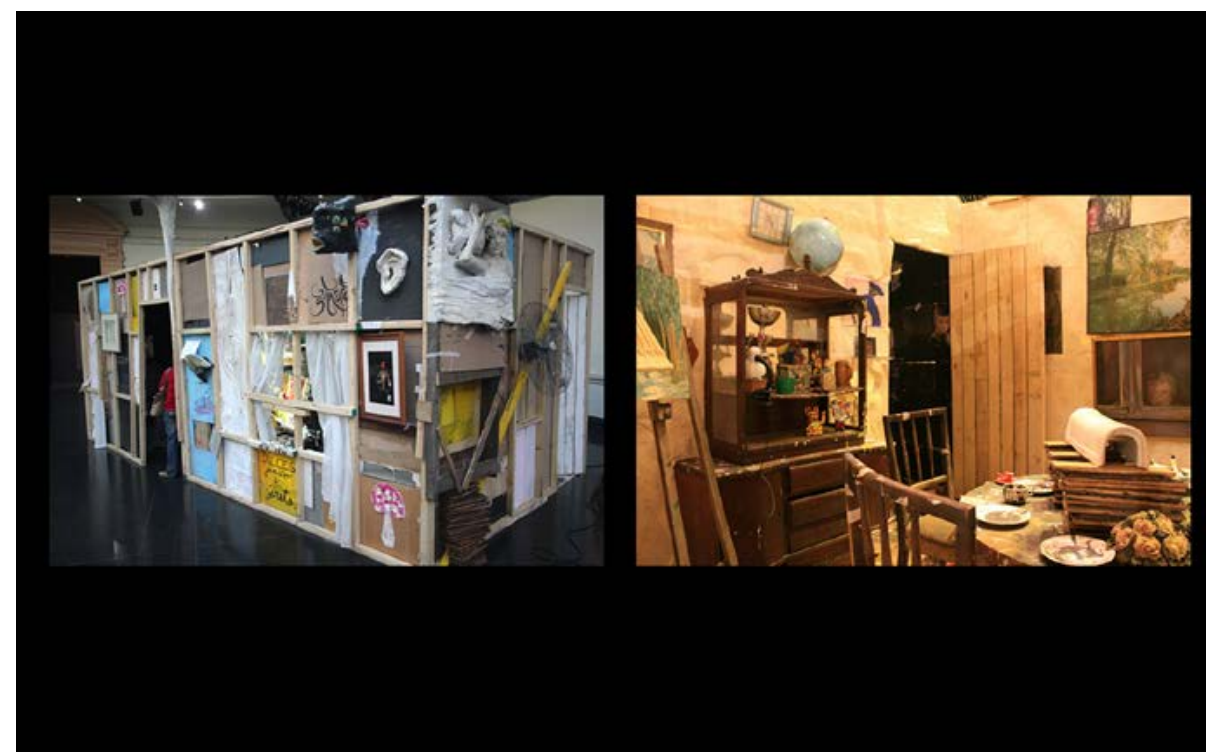

Figura 6. Exterior e interior de set de La Casa Lobo, en la Bienal de Artes Mediales, Santiago, Chile. 2017. http://leoncocina.com/la-casa-lobo-en-la-bienal-de-artes-mediales/

\section{CONCLUSIONES}

Observamos que en los últimos años emerge una atención particular hacia el sustento sonoro de lo fílmico que se manifiesta tanto desde la producción cinematográfica, en la que el cine de la cineasta argentina Lucrecia Martel será paradigmático, como desde las teorías e investigaciones del cine, que habrían descuidado las atmósferas sonoras en los estudios en torno a este arte. En ese sentido, los estudios realizados por Alcoz (2017), Chion (1993), Jullier (2007) y Szendy (2015) fueron fundamentales en el momento de establecer un sustento teórico a nuestras intuiciones y percepciones alrededor de estos largometrajes.

Nos aproximamos a estos filmes, a la vez experimentales y narrativos, rodeando la imagen, para instalarnos de modo más concreto en el lugar de lo audible, particularmente porque se trata de obras en las que este sustrato no está subyugado a la imagen, sino que comunica en igual medida. La esfera de lo acústico, en esta obra tan plástica y tan concerniente a las artes visuales, posee en Lucía, Rey y La casa lobo un estatuto fundamental sin el cual no habría posibilidad de narración. Identificamos, para cada filme, distintos contrapuntos sonoros que dan cuenta de una correspondencia ineludible entre el sonido y la imagen. La composición y figuración, entonces, no pertenece exclusivamente al campo de lo visual, sino que el sonido tendrá un rol predominante que se manifiesta, según observamos (o más bien, escuchamos), desde distintos lugares: la utilización de la música, la presencia única o múltiple de la narración en off; los ruidos y los sonidos acusmáticos; las tensiones entre campo y fuera de campo; la posibilidad de hacer visibles los materiales de construcción del medio audiovisual, el uso estratégico del silencio; las representaciones sonoras del paso del tiempo. Dispositivos acústicos que van ajustando y desajustando, mediante estas estrategias, la dicotomía entre lo visual y lo sonoro. La desavenencia entre lo que vemos y lo que oímos es parte de la ecuación fundamental en el momento de provocar una extrañeza, que protagoniza los tres filmes, y que se justifica tanto desde el lugar de la narración como de los contextos históricos y políticos a los que alude cada una de las películas. 


\section{NOTAS}

1. Para Nöel Burch, el modelo de representación institucional se establece muy temprano en el siglo XX, en los albores de la existencia del cine, y tiene relación con una comprensión canónica del lenguaje del cine que se ha normalizado, no solo en los Estados Unidos y en la industria hollywoodense, sino también expansible para todo el mundo según ese modelo hegemónico. Se trata de un modelo narrativo y representacional que se ha desarrollado en conjunto con la industria del cine norteamericano.

2. La cita es la siguiente: "Desde un punto de vista físico, el sonido es una perturbación que hace fluctuar la presión del aire a la altura del oído" (Jullier 2007, 41).

3. Chion caracteriza esta escucha en la que "se oye el sonido sin ver la causa" (1993, 32).

4. En su imagen-tiempo, Deleuze propone: “Es probable entonces que el cine sonoro modifique la imagen visual: en cuanto oído, 'hace ver' en ella algo que no aparecía libremente en el cine mudo" $(1987,298)$.

5. Algunos fragmentos y obras de la productora se pueden ver en http://diluvio.cl/.

6. En una entrevista de 2016 para la revista Solomonos Magazine, los directores entregan mayores detalles de estos flujos de trabajo, que pueden consultarse en https://solomonos.com/home/diluvio/.

7. A pesar del estatuto experimental de estas obras, son películas que dialogan con el corpus de cine de ficción chileno contemporáneo, que toman como punto de partida un evento coyuntural del presente social de Chile, esto es, abocan a representar críticamente nuestro pasado. Estos temas abordan un amplio rango, desigualdad social, crisis de las instituciones, conflictos de identidad y género, a partir de vinculaciones del documental con la ficción, como el uso de no actores, material de archivo, etc. Se trata de una tendencia importante del cine chileno actual, a la cual, desde un proyecto estético muy distinto, ingresan estas películas.

8. Colonia Dignidad es un asentamiento situado en la zona sur de Chile, fundado por un exmilitar nazi, Paul Schäfer, que posteriormente fue ocupado por miembros de la dictadura chilena como centro de tortura y crímenes de lesa humanidad. A su vez, Schäfer fue acusado de abuso sexual y La casa lobo da cuenta de ello.

9. El autor hace una conceptualización que efectúa el teórico norteamericano P. Adams Sitney, quien se refiere al structural film como un "cine delimitado por los rasgos que condicionan el dispositivo tecnológico del medio [...] las obras resultantes son filmes no narrativos" (Alcoz 2017, 43). Si bien Sitney descuida el análisis sonoro de estos filmes, haciendo hincapié en aspectos básicamente visuales, Alcoz analiza las películas particularmente desde su sonido.

10. Tassara aborda, a partir de las transformaciones que está atravesando el espacio de la visualidad, el concepto de metaplasmos ligado a la oralidad y al lenguaje. "El metaplasmo es una operación que altera la continuidad fónica o gráfica del mensaje, es decir, la forma de expresión en tanto que [sic] manifestación fónica o gráfica" $(2016,3)$.

11. Al igual a como ocurre en La casa lobo, la figura de la casa será protagónica. Aquella casa que el filósofo Gaston Bachelard (2000) configura como el lugar de los recuerdos tendrá distintas connotaciones en las dos películas, y serán elementos esenciales en el momento de proponer un contrapunto psicológico de los personajes.

12. La rotoscopía es una técnica de animación en la que se interviene manualmente cada fotograma de video, ya sea dibujando, pintando o modificándolo de cualquier otra forma. Además de sus fines estéticos, se utiliza para realizar efectos especiales, o para calcar movimientos de captura fotográfica y ser traspasados a técnicas de animación. En el caso de Rey, la intervención es hecha de manera análoga, como un recurso formal con sentido a partir de la narrativa.

13. Este filme en particular opera con algunos principios del found footage filme, pensando particularmente en los trabajos de Bill Morrison y de PeterTscherkassky.

14. Aclaramos que se trata de una autorreferencialidad enmarcada en la ficción; los sonidos son los que provocan y activan esta ficción. Pero no se insertan, por ejemplo, las voces de los artistas mientras trabajan, o el sonido ambiental del museo, con sus espectadores que observan y comentan la obra, y que, incluso, a veces la manipulan. 


\section{REFERENCIAS}

Alcoz, Albert. 2017. Resonancias filmicas: el sonido en el cine estructural (1960-1981). Madrid: Shangrila.

Atallah, Niles (Director). 2007. Lucía. Chile: Niles Atallah, Francisco Albornoz.

— 2017. Rey. Chile: Coproducción Chile-Francia-Países Bajos (Holanda)-Alemania-Qatar.

Bachelard, Gastón. 2000. Poética del espacio. Buenos Aires: Fondo de Cultura Económica.

Baus, Martín. 2018. "La ley del desajuste: decalaje, emancipación y reverberancias del sonido en el cine chileno." Campo contra Campo. http://campocontracampo.cl/textos/12.

Bellour, Raymond. 1999. "La doble hélice". http://campostrilnick.org/wp-content/uploads/2012/02/La-dobleh\%C3\%A9lice1.pdf.

- 2009. Entre imágenes: foto, cine, video. Buenos Aires: Coluhue.

Burch, Noel. 2006. Praxis del cine. Madrid: Fundamentos.

Bresson. Robert. 1979. Notas del cinematógrafo. México: ERA.

Chion, Michael. 1993. La audiovisión: introducción a un análisis conjunto de la imagen y el sonido. Bercelona: Paidós.

- 1995. La música en el cine. Barcelona: Paidós.

Cociña, Joaquín y Cristóbal León (Directores). 2018. La casa lobo. Chile: Diluvio.

Deleuze, Gilles. 1987. La imagen-tiempo. Barcelona: Paidós.

- 2002. Francis Bacon: la lógica de la sensación. Madrid: Arena.

Di Bella, Daniela V. 2018. "Ex obra, la rematerialización de la imagen en movimiento". Cuadernos del Centro de Estudios en Diseño y Comunicación. Ensayos 66: 1-10. http://www.scielo.org.ar/scielo.php?script=sci_ arttext\&pid=S1853-35232018000100009

Jullier, Laurent. 2007. El sonido en el cine: imagen y sonido; un matrimonio de conveniencia. Barcelona: Paidós.

Lippit. Akira Mizuta. 2012. “Ex-Cinema: From a Theory of Experimental Film and Video". Berkeley: University of California Press.

Reyes, Juan. 2005. “Háptica y sonido: introducción a la síntesis escaneada”. https://www.maginvent.org/ articles/hapticscan/hapticscan.html.

Szendy, Peter. 2015. En lo profundo de un oído: una estética de la escucha. Santiago de Chile: Metales Pesados.

Tassara, Mabel y Kirchheimer, Mónica, comps. 2016. Animación: encuentros de lenguajes, géneros y figuras. Buenos Aires: Imago Mundi.

Youngblood, Gene. 2012. Cine expandido. Buenos Aires: Universidad Nacional de Tres de Febrero. 